\title{
An Econometric Analysis of the Relationship between Education and Economic Growth in China
}

\author{
Xueyan Chang \\ School of social sciences, University of California, Irvine, Irvine 92617, the U.S \\ Amberchangxy@163.com
}

\begin{abstract}
Historically, economists had already emphasized the importance of human capital to the development of a country. Under the contemporary knowledge-based socio-economic background in China, education, as an essential and fundamental element in human capital development, is reasonable to be connected with economic growth. To testify this argument and figure out the inner relationship, I built a linear regression model by using China's provincial data in the past twenty years and the result generated by Eviews has confirmed a convictive positive correlation between education and economic growth in China. This research as well attests the significance of China's strategy "develop the country through science and education". Additionally, the result of this research that education takes positive effect on national development is similar with the achievement of numerous previous international published researches. Therefore, the improvement of education system is a significant step to realize our country's great renaissance.
\end{abstract}

Keywords: regression analysis, economic growth, education, human capital.

\section{Introduction}

Human capital is an important concept which determines the economic growth of a nation. As the author of the human capital theory, Theodore W. Schultz had pointed out that the tight connection between the progress of workers' knowledge and American agricultural output, which is a primitive support to the argument that enhancing human capital is more capable to push economic growth than physical capital accumulation [1]. Karl Marx had also introduced a crucial concept "Labor power" similar to the human capital in his thesis. Unlike the word "Labor", "Labor power" pays more attention to the ability to work existing in a human being consisting of both mental and physical capabilities [2], thus a cumulated experience is significant to improve the "labor power". In the 21 st century, with the acceleration of the economic globalization, the international competition among countries gets tougher and tougher. Chinese economist Zhao Lvkuan indicated that the competition of human capital is a vital component of the modern international competition [3]. Therefore, enhancing the human capital has a non-negligible effect on improving the comprehensive national power and the economic growth. According to the human capital theory, the formation of the human capital could be considered as a progress of investment [1,4]. Receiving a higher education is a persuasive way to accumulate human capital because students can get systematic, academic knowledge and also a clearer cognition toward the operation of the entire society. Through familiarizing students with the subject specialization, the country may have professional talents on different domains and improve the overall national productivity by technology advance. Consider that China has a demographic dividend, the transformation from the advantage of the population to the advantage of the human capital is certainly a key issue determining Chinese development [5]. Our state leaders had realized the importance of encouraging the education to the state's growth long ago. In 1995, the strategy "develop the country through science and education" was introduced in the national scientific conference, informing that the technology is "the first productivity" and the education should be valued as the base of development [6]. However, exploring Chinese human capital keeps facing several noteworthy problems: relatively low national education level and cultural and scientific qualities, the great gap of education resources between urban and rural areas exists, the inflexible educational mechanism [5]. To study further on the importance of education for Chinese economic growth and test the reasonableness of strategy "develop 
the country through science and education", I would like to use Chinese interprovincial data to explore the inner relationship between the economic development and the education in the below section.

\section{Method}

To obtain the relationship between the national economic development and the number of general higher education graduates, I adopt the panel data from thirty-one provinces in China within twenty years. Therefore, the sample size is equal to $(31 * 20=) 620$. A larger sample size is necessary to reduce the bias thus improve the linear regression equation's accuracy.

The model is $\mathrm{Y}=\beta 0+\beta 1 * \mathrm{EDUC}+\beta 2 * \mathrm{TECH}+\beta 3 * \mathrm{TRADE}$.

EDUC represents the number of general higher education graduates. The statistics of variable "EDUC" is shown as Table 1. The data is from the National Bureau of Statistics of China.

Table 1. The Statistic Table of Variable "EDUC"

\begin{tabular}{|c|c|c|c|c|c|}
\hline Mean & Median & Maximum & Minimum & Std.Dev & Observations \\
\hline 11.38445 & 6.855000 & 48.41000 & 0.080000 & 11.41723 & 620 \\
\hline
\end{tabular}

First, I set the real gross regional product as the dependent variable, "Y". The National Bureau of Statistics of China offers the nominal gross regional product and the consumer price index. However, the price index here is using the last year as the base year. On this basis, I recalculate the consumer price index which is setting the data of 1996 as the base year $(1996=100)$. Then the real gross regional product of each province in each year is equal to the result of the nominal one dividing by the new consumer price index times 100 [7]. The statistics of variable $\mathrm{Y}$ is shown as Table 2. The real value has been adjusted for inflation for comparing the gross output without price changes.

Table 2. The Statistic Table of Variable "Y"

\begin{tabular}{|c|c|c|c|c|c|}
\hline Mean & Median & Maximum & Minimum & Std.Dev & Observations \\
\hline 7596.223 & 4694.439 & 54425.62 & 64.98000 & 8701.737 & 620 \\
\hline
\end{tabular}

Afterwards I adopt two independent variables to lessen other factors' influence on the economy: number of patent acceptance and the total value of foreign trade in each province.

Technological innovation is a significant factor determining the economic growth. Chinese patent system stimulates the technological development effectively, and it offers relatively convictive database in technology innovation [8]. Therefore, the number of national patent acceptance in each region could reflect its technological innovation level which has a large effect on the regional output, and I indicate it by "TECH" in the model. The statistics of variable "TECH" is shown as Table 3. The data is from the National Bureau of Statistics of China.

Table 3. The Statistic Table of Variable "TECH"

\begin{tabular}{|c|c|c|c|c|c|}
\hline Mean & Median & Maximum & Minimum & Std.Dev & Observations \\
\hline 25283.41 & 5633.00 & 504500.0 & 10.00000 & 57207.35 & 620 \\
\hline
\end{tabular}

Additionally, Chinese foreign trade maintains a rather rapid growth since the reform and opening-up policy, generating a positive effect on the economic development. There are a lot of documents demonstrating that both import and export enable the acceleration of economic growth [9], so I adopt the total value of import and export in each area as a control variable to improve the regression equation's accuracy. It is denoted by "TRADE" in the model. The statistics of variable "TRADE" is shown as Table 4. The following data is from the National Bureau of Statistics of China.

Table 4. The Statistic Table of Variable "TRADE"

\begin{tabular}{|c|c|c|c|c|c|}
\hline Mean & Median & Maximum & Minimum & Std.Dev & Observations \\
\hline 61185659 & 11846549 & $1.09 \mathrm{E}+09$ & 92910.00 & $1.41 \mathrm{E}+08$ & 620 \\
\hline
\end{tabular}


Finally, I obtain the linear regression equation with multiple variables via EViews. The t-statistic of each variable reflects its significance, and its coefficient's sign symbol could show the fact whether the variable impacts positively or negatively on Y. The adjusted R-squared tells about how well the regression equation is on predicting the actual value. As a conclusion, I can infer the relationship between the number of general higher education graduates and the regional economic growth.

\section{Result}

The regression result produced by Eviews is shown as Table 5.

Table 5. The Regression Result produced by Eviews

\begin{tabular}{lcccc}
\hline Variable & Coefficient & Std.Error & t-Statistic & Prob. \\
C & 703.1538 & 124.2277 & 5.660201 & $<0.0001$ \\
EDUC & 433.5221 & 10.03850 & 43.18594 & $<0.0001$ \\
TECH & 0.027798 & 0.002813 & 9.881946 & $<0.0001$ \\
& & & & \\
TRADE & $2.21 \mathrm{E}-05$ & $1.00 \mathrm{E}-06$ & 22.04335 & $<0.0001$ \\
\hline \multirow{2}{*}{ R-squared } & 0.940231 & & Mean dependent var & 7596.223 \\
Adjusted R-squared & 0.939940 & & S.E. of regression & 2132.549 \\
F-statistic & 3230.113 & & Prob(F-statistic) & $<0.0001$ \\
\hline
\end{tabular}

EDUC is the number of general higher education graduates, TECH is the number of national patent acceptance in each region, and TRADE stands for the total value of import and export in each area.

According to the table 5 we can get the linear regression equation is $\mathrm{Y}=703.1538+$ $433.5221 * \mathrm{EDUC}+0.027798 * \mathrm{TECH}+2021 \mathrm{E}-05 * \mathrm{TRADE}$, and every variable is significant because each t-statistic is large enough and the probabilities are all less than 0.0001 meaning their coefficients are nearly impossible to be zero. The coefficient of EDUC is 433.5221 , a positive number, thus there is a positive relationship between the EDUC and the dependent variable, the real gross regional product. The adjusted R-squared is 0.94 , which can tell the model fits the data well.

However, the multicollinearity may exist because I have not excluded the possibility that the number of general higher education graduates may impact the number of national patent acceptance. In general, the people with higher education are more likely to invent new technology comparing with the people without it. Perhaps we can change an expressive way: There are many theories concerned with the economic growth, in here, the number of graduates stands for the human capital, and the number of patents signifies the technologic innovation $[8,10]$. Therefore, they represent different aspects and do not conflict with each other.

\section{Conclusion}

Through the regression analysis, the positive relationship between education and the economic growth has been proved. Even more remarkable, the significance of education's contribution to the economic development is prominent. The strategy "develop the country through science and education" is suitable for our national condition and worth being implemented seriously. To sufficiently take the advantage of Chinese large population, increasing our overall population quality should be emphasized and realized by exploring human capital. A lot of historical evidences prove that the rapid accumulation of human capital is an important factor to promote the economic growth [5].

Education, as an effective investment, plays an essential role in forming human capital. In the 21 st century, every country pursues a strong economy with optimized growth potential, and they all realize that the primary basis is well-educated workforce [11]. Jorgenson D W and Fraumeni B M measured the impact of investment on education on U.S. economic growth and illustrates that constant educational investment will maintain a predominant requirement for rapid economic growth [12]. Professor lan Diamond introduces the situation in the U.K.: widening participation in university study 
results in stronger economic growth [11]. Lee E K analyzed the statistical output generated by SPSS and concluded the positive connection between education and economic development both in Japan and South Korea[13]. Yang Jian-fang, Gong Liu-tang and Zhang Qing-hua designed an economic model in which both human capital accumulation speed and human capital stock could contribute to the economic growth by studying the data from China's different provinces, then they discovered that the human capital accumulation contributed more to the marginal economic growth than the physical capital [14]. Cai Zeng-zheng's research analyzed the relationship between education and the economic growth based on the data from 194 countries with different development level, and all of them showed that education had a positive effect on the economic growth [15]. All the researches above testify the reliability of my research by supporting the similar argument of the education's importance to the economic growth. Therefore, I conclude that sticking with the strategy "develop the country through science and education" is essential to our country's development with the background of knowledge-based economy nowadays [16]. The specific measures should include: constructing a complete system of education, advocating the whole developmental education, developing the human capital investment market and so on $[17,18]$. However, the detailed policies a country should develop in education should be considered in opportunity cost and evaluation of long-run benefit. Generally, the input-output ratio on education investment in China is relative higher than investment on infrastructure construction [19].

\section{References}

[1]. Schultz T W. Investment in Human Capital[J]. Journal of Political Economy, 1973, 82(Volume 81, Number 4):787.

[2]. Karl Marx. "Economic Manuscripts: Capital Vol. I - Chapter Six". marxists.org

[3]. Sinoss. Zhao Lvkuan: "Human Resource is the basis of Chinese strength"[EB/OL]. https://www.sinoss.net/2004/0331/2452.html,2004-03-31

[4]. Zhang Zhen-qi, Sun Lin-yan. The Research of High Education and the Exploration of Human Capital[J]. China Soft Science, 2002(11):30-33.

[5]. Seminar of Report on Issues of Chinese Education and Human Resources. Stepping from large country in population to a powerful country in population — Summary of Report on Issues of Chinese Education and Human Resources[J]. Journal of Higher Education, 2003(3):1-14.

[6]. Wang Zhi-xin. Carring Out the Strategy of Invigorating the Country through Science, Technology and Education --- Establishing the Advanced System of Science Research and Higher Education[J]. Science \& Technology Review, 2010, 28(8):3-3.

[7]. Feenstra R C, Deng H. Estimating Real Production and Expenditures across Nations: A Proposal for Improving the Penn World Tables[J]. Review of Economics \& Statistics, 2007, 91(1):1-28(28).

[8]. Liu Hua. Patent System and Economic Development: Theory and Reality --- Analysis on the Dynamic Utility of China's Paten System [J]. China Soft Science, 2002(10):26-30.

[9]. Yang Feng. An Analysis of the Relationship between the Chinese Foreign Trade and Economic Growth[J]. Foreign Investment In China, 2011(11):126-127.

[10]. Fan Q,Goetz SJ,Liang J. The Interactive Effects of Human Capital and Quality of Life on Economic Growth[J]. Applied Economics, 2016(53):1-15.

[11]. Brown P, Lauder H, Ashton D. Education, Globalisation and the Future of the Knowledge Economy.[J]. European Educational Research Journal, 2008, 7(2):131-156.

[12]. Jorgenson D W, Fraumeni B M. Investment in Education and U.S. Economic Growth.[J]. Scandinavian Journal of Economics, 1990, 10(94):51-70.

[13]. Lee E K. HIGHER EDUCATION EXPANSION AND ECONOMIC GROWTH IN JAPAN AND SOUTH KOREA[J]. 2012. 
[14]. Yang Jian-fang, Gong Liu-tang, Zhang Qing-hua. Human Capital Formation land its Effects on Economic Growth[J]. Management World, 2006(5):10-18.

[15]. Cai Zeng-zheng. The Econometric Analysis of Education's Contribution to the Economic Growth[J]. Economic Research Journal, 1999(2):39-48.

[16]. Hui Yong-zheng. Knoeledge-based Economy and Develop Country Through Science and Educstion[J]. Science and Society, 1998(3):3-7.

[17]. Zhong Qi-quan, Cui Yun-huo, Zhang hua. For every student's development[J]. Global Education Outlook, 2001, 30(2):3-8.

[18]. Qin Shuang-suo. Incestment in Human Capital[J]. Economy and Management, 2000(3):15-16. [19]. Yuan Lun-qu, Tu Qi-song. Educaiton Investment and Economic Growth[J]. Human Resources Development of China, 2000(3):8-11. 